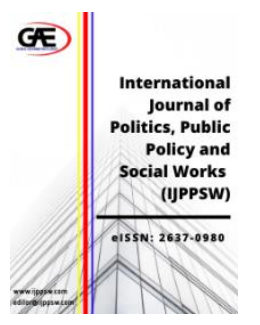

INTERNATIONAL JOURNAL OF
POLITICS, PUBLICS POLICY
AND SOCIAL WORKS
(IJPPSW)
www.ijppsw.com

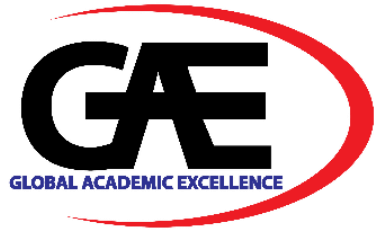

\title{
INTER-CULTURAL MARITAL RELATIONSHIP: RECRUITING PARTICIPANTS FROM BANGLADESHI COMMUNITY
}

\author{
A. M. Sultana ${ }^{1}$ \\ ${ }^{1}$ Department of Journalism, Universiti Tunku Abdul Rahman, Malaysia \\ Email: sultana@utar.edu.my
}

\begin{abstract}
Article Info:
Article history:

Received date: 18.04 .2021

Revised date: 25.04 .2021

Accepted date: 05.05.2021

Published date: 15.06 .2021

To cite this document:

Sultana, A. M. (2021). Inter-cultural Marital Relationship: Recruiting Participants From Bangladeshi Community. International Journal of Politics, Publics Policy and Social Works, 3 (9), 09-16.
\end{abstract}

DOI: $10.35631 /$ IJPPSW.39002.

This work is licensed under CC BY 4.0

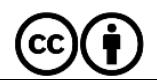

\begin{abstract}
:
Inter-cultural marriage is increasingly common in many societies, yet intercultural relationships remain at a higher risk of failure, with higher divorce rates and lower marital satisfaction. The present study analyzed a growing phenomenon in Bangladesh and Malaysia known as intercultural or mixed families. The main objective was to explore challenge associated with intercultural relationships, and to determine how these relate to marital satisfaction among foreign partners in inter-cultural families. This study explores five intercultural married couples' experiences using a qualitative inquiry. In this study, we demonstrated the condition of inter-cultural married couples by examining their challenges with respect to inter-cultural adjustment, religious practice, and parental commitment.
\end{abstract}

Keywords:

Inter-Cultural Marriage; Marital Satisfactions; Bangladesh, Malaysia, Cultural Adjustment

\section{Introduction}

There is a growing phenomenon of inter-cultural marriages in many countries (1). An intercultural marriage between two different cultures may face double challenges because both partners tend to have difficulties related to language and religious barriers, cultural constraints, marital satisfaction, and parental commitment. Inter-cultural couples engage in a relationship form, the 'new' family becomes enclosed by a mixture of different values, beliefs, customs, and lifestyles. Therefore, a mixture of different values, beliefs, customs, and lifestyles of intercultural couples starts out their relationships with a higher risk for an unsuccessful union (2). In some cases, these situations contribute to marital dissatisfaction and divorce $(2,3)$. 


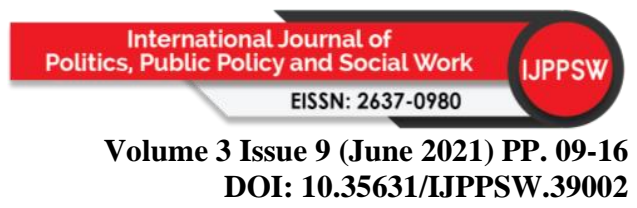

Studies show that Inter-cultural married couples remain at a greater risk of domestic violence compared to same culture couples (4). Similarly, children of inter-cultural relationships tend to have a higher risk for parental abductions than children from same-culture couples (3). Several studies argued that inter-cultural marriage as beneficial in contributing towards social cohesion in the society. It creates new generations that are more open towards others, as well as the possibility of producing progeny who is more advantageous in terms of intelligence, beauty, emotional and behavioral stability $(5,6)$. Some studies contribute the negative views on intermarriage. These studies show that there is low marital satisfaction and a higher rate of conflict $(7,8)$. Studies revealed that intercultural marriage tend to have different values, beliefs, customs, and lifestyles which starts the relationships with a higher risk for an unsuccessful marital relationship (2). In some cases, these contribute to marital dissatisfaction and divorce $(2,3)$.

The study attempts to draw a deep description of how inter-cultural married couples experience their relationships in the Malaysian context. To achieve the research objective of understanding inter-cultural married couples' experience, the study has chosen a qualitative approach It is appropriate as qualitative research sees the world as experienced by people in their interactions with each other $(9,10)$. According to this paradigm the nature of inquiry is interpreted, and the purpose of an inquiry is to understand a particular phenomenon, not to generalize to a population (11).

\section{Literature Review}

Recent studies show that intercultural marriages is increasing in the United States $(12,13)$, Australia (14,15), and Canada (16), among other countries in Europe. Another study revealed Inter-cultural marriage is a growing phenomenon in Europe, America, and East Asia. Studies show that In Helsinki, such marriages are more common, currently at the rate of 12 percent, and marriages between Finnish national and a foreign national comprised 15 percent of all marriages in Helsinki in 2011 (17).

With respect to the factors that influence on inter-cultural marriage, researchers have long viewed inter-cultural relationships as evidence of status-caste exchange (18). This theory suggests that people of the dominant racial group exchange their racially based social status for another resource such as beauty and novelty provided by individuals of the minority race (19, 20). These studies argued that individuals from the minority race must therefore offer something extra to the relationship to reward for the higher status of individuals from the dominant race. The present study can be also related to the study was developed by Marriage, Becker $(21,22)$ assumes that people marry to maximize their own well-being, benefits of marriage are more efficiently utilized when individuals match up with others of similar traits. In his or her social interactions, an individual seeks to maximize 'social income', which is own income plus the value of his or her social environment (23). Thus, apart from factors such as education and religion, there may be benefits arising from cultural similarities in marriage.

Intercultural couples face the challenges of cultural adjustment. The process of marrying from different cultures is the process of negotiation as this couple represents the transition from dual individuality to a partnership within the relationship (24). A recent study argued that Intercultural partnership requires replacement of individual psychological realities into a conjoint marital reality (25), and for intercultural couples, this often requires the negotiation. It has been argued that Inter-cultural marriage tends to have impact on marital relationship, raising children and family well-being. What inter-cultural marriage effects on marital Copyright (C) GLOBAL ACADEMIC EXCELLENCE (M) SDN BHD - All rights reserved 


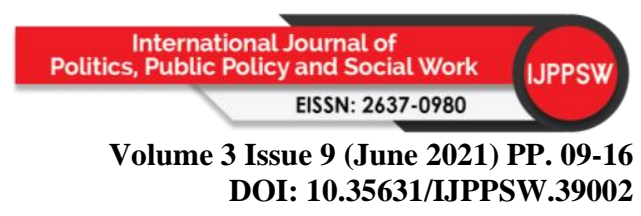

relationship, raising children and family well-being that we understand what lies behind the phenomenon. Marriages between individuals of different cultures reflect social interaction and social acceptance between social groups (26). Other studies showed this might result in cultural conflict as the children's perspectives might differ than that of their parents (27).

\section{Research Methodology}

The study has adopted a qualitative research design. I used two techniques for data collection such as depth interview and participant observation using the semi-structured interview as a tool to collect the data. A deeper understanding of inter-cultural married couples' experiences is important on how they deal with their marital relationship, cultural adjustment, and parental commitment.

The author has the experiences of living in the Bangladeshi community and had the opportunities interacted with many inter-cultural married couples. The topic was chosen because inter-cultural marriage is a growing phenomenon in Malaysia. Although inter-cultural marriage tends to have a positive impact on building social cohesion and contributing to social integration, these marriages are at a greater risk for domestic and divorce (28). In line with this background, a deeper understanding of inter-cultural married couples' experiences is important in how they deal with their marital relationship. We focused on inter-cultural marriage in two Muslim countries - Malaysia and Bangladesh. As a part of the community, I was interested to explore how inter-cultural married couples' relationships in the Muslim country context. The author's experiences of living in Bangladeshi community have been extremely valuable in shaping her analysis of inter-cultural relationship.

\section{Sampling Methods}

A total of five intermarriage couples were interviewed using a snowballing sampling technique. The respondents in this are intercultural married couples. Participants were recruited from Kuala Lumpur, the capital of Malaysia. One important criterion for the respondents in this study was that the respondents of this study intermarried families belonging to Malaysian brides or grooms who marry a person who is from Bangladesh. The respondent's age range was between the ages of 24 and 60 years. We recruited all the respondents through my friendship networks and snowballing techniques.

\section{Research Procedure}

The research is based on community-based settings. The participants have been recruited through my friendship networks in my community. I obtained the consent through social networking sites and phone calls. The main technique for the study was an in-depth interview. I have conducted in-depth interview with five inter-cultural married couples. Husband and wife were interviewed separately, and the interview was conducted on Sunday or another public day in their houses and community social gathering events. Each interview usually lasted between 30 minutes and one hour.

The interview session was tape-recorded with the consent of the respondents. It was observed that some respondents were feeling uncomfortable when tape recorder was used. Once the respondent had started to talk, they forgot the tape-recorder we usually used. In this way there was nothing to divert me from the interview itself. After the interview session, we noted down some details about the talk and the situation in general. However, this method not only gave me the opportunity to listen how inter-cultural married couples formulated themselves in a discussion, but also to draw inferences from observing how they interacted with each other. 


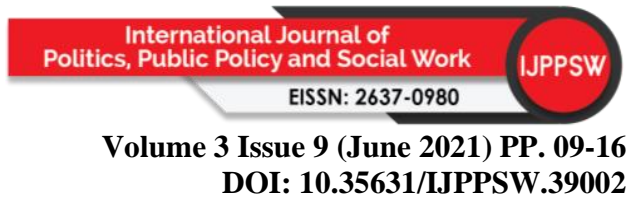

Method in Action

Several considerations arose when using depth interviews and participant observation as tools to collect the data. The interview questions were framed careful and avoided response bias. Sometimes, we had to deal with unexpected answers and therefore it was required to modify the interview questions. The interview was conducted individually to each respondent in their household.

My experience of interviewing inter-cultural married couples was extensive. Using the narrative approach, we encouraged participants to share their experiences, their marital satisfaction, parental relationship, and their relationship with the wider community. By using a qualitative approach and a narrative design, we have learned the following lessons that could help to others for further investigation: In carrying out this qualitative research, we have added our experiences that reflected on how we interpreted the data. Upon reflecting my own experiences, it is believed that conducting a good quality of qualitative research, it is important to share the researcher's own experience.

Studies support that the credibility of the researcher is especially important in qualitative research, as it is, he or she who is the major instrument of data collection and analysis (29). Participant observation has been used as a tool to gather information. As the researchers, we had the opportunities to get an insight into inter-cultural married couple's lives closer. During the conversations, we observed the daily activities of the respondents within their homes. During data collection and staying in the field, different incidents that happened in a natural setting were observed and recorded by the researcher. Through this observation we were able to realize the respondent's real situation in their own contexts. We, therefore, was able to examine respondent's situation critically.

Through this qualitative practice, it is possible to obtain a more holistic picture of the issues. As researchers, we need to be patient and be able to show respect to the participants so that the participants can trust us. These would assist us to capture their feelings. Through this research we obtained a more holistic picture of the issues, which could be an important lesson for the researchers. This research process might be helpful for other researchers to build more creativity in qualitative research. Through this qualitative practice, it is possible having positive results and obtaining a more holistic picture of the issues.

\section{Results and Discussion}

\section{Demographic Profile of The Respondents}

The demographic information includes ethnicity, religion, education level, employment status, years of marriage, and how many children the respondents have at the time of research. Most of the respondents were from the middle-class. The respondent's age range was between the ages of 24 and 60 years. Concerning religious status, respondents tend to have only Muslim. The respondent's number of children was between the ages of 2 to 4 children only.

\section{Factors Influence Inter-Cultural Relationship}

Regarding marriage's concern, we noted that most of the respondents considered their marriage based on their love and mutual understanding and they were pretty concerned about their different cultures. From the interview, most of the couples reported that they attracted each other by their personality. 


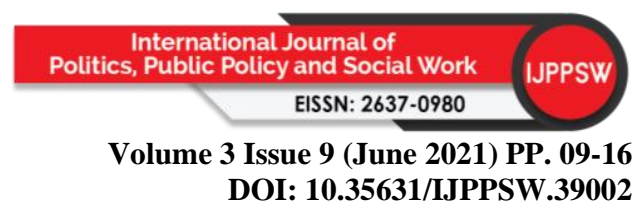

According to respondent 1 "My wife tended to have a great personality; she was a passive lady that attracted me to marry her". Another respondent also attracted to his wife's personality when they met each other in the army camp. He stated that: "I was attracted to her independent and active personality". Similarly, another respondent was attracted by his wife's personality. He further elaborated "Her polite behaviour and morality and always being nice to others attracted me to marry her".

Although all male respondents are attracted to their wives' personality, results showed that most of female attracted by their husband's appearance. For instance, one female respondent claimed that "He looks so handsome when saw him for the first time". Similarly, another female respondent claimed that she was attracted by his husband's intelligence and merit.

\section{Exploring Inter-Cultural Married Couples' Challenges}

\section{Communication in Intercultural Marriages: Managing Language Barriers and Cultural Difference}

With regards to dual languages, it was difficult and stressful situation s for the children to cope with two languages. Generally, children in intermarriage families tend to follow the mother language. The mother's culture was observed as the dominant culture in these families. This study also revealed that there was not much difficulty for children to speak in their mother tongue. However, difficulty and tension occurred when the children needed to communicate with their relatives from the father's side. Challenges in inter-cultural marriage may double when both partners faced a language barrier impacts on communication with children and family members.

These may contribute to marital satisfaction and parental commitment. Literature supported that a mixture of different values, beliefs, customs and lifestyles of inter-cultural couples starts out their relationships with a higher risk for an unsuccessful union. The findings of the study showed there is a language barrier among the respondents.

Most husbands made significant efforts to learn the language. One respondent Mizan Hoque who tried to learn some Malay language to communicate with his mother-in-law. It is interesting to note that husband tried to learn Chinese, the wife also tried to learn her husband's language. It could be said that inter-cultural married couples are willing to teach each other languages to communicate with their spouse and family members. The results revealed that the husband put effort into learning his wife's culture to keep his marital relationship and to perform the role as a parent to their children. However, in some respects, wives were regarded positively to family bonding.

\section{Eating Habits}

Inter-cultural couples must adjust themselves as they are two different people who grow up in a different cultural background and have different eating habits. As remarked by a husband who is from Bangladesh stated that he will eat all the foods cooked by his wife as he used to eat Malaysian food. However, he never forced his wife to follow his eating habits. Similarly, another respondent, Mr Ali, shared that he eats what his wife cooks.

However, another respondent Amalina, tends to change her cooking style to satisfy her husband's eating habits. Her husband likes to eat Bangladeshi food. Thus, inter-cultural married couples are more willing to tolerate each other when comes to eating habits. It can Copyright (C) GLOBAL ACADEMIC EXCELLENCE (M) SDN BHD - All rights reserved 


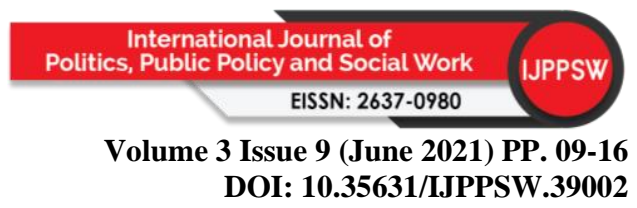

summarize that these couples put efforts into adjusting each other eating habit to strengthen family relationships. They wanted to carry on both traditions and culture in their eating habits.

\section{Marital Relationship and Raising children}

It has been observed some inter-cultural couples refused to attend social gatherings where they need to meet the community. Once they married, they become to be isolated themselves from the community. Thus, the biggest obstacle faced by the inter-cultural community is societal negative attitudes.

Wives faced more challenges when they needed to deal with the school-going children. Their children always wondered from where their father came. The respondent preferred to introduce the father as the white man rather than a Bangladeshi because of the stigma attached and negative attitude towards the nation. Even in some cases the wife was thinking "turning off" from the job and settled a third country where they might not require facing such question. Some couples stressed balancing between the two cultures and traditions.

They were concerned that practicing two languages and cultures would be confusing to the children. It was observed that children in inter-cultural married couples followed the mother's culture. Even it was observed that the children rarely familiar with their father's culture and practices.

\section{Conclusion and Implication}

The study aimed at exploring the experiences of inter-cultural married couples in their marital relationships and possible challenges using a qualitative inquiry. The findings of the study suggest that couples shared similar experiences around their marital satisfaction, cultural differences, and language barriers that they faced in their families. Some couples emphasized the balancing between the two cultures and traditions. They were concerned practicing two languages and cultures would be confusing to the children. In most of the cases it was noted that children in inter-cultural married couples adopt their mother's culture and they are rarely familiar with their fathers' culture and practices.

The study suggests that it might be beneficial to investigate the contextual circumstances in which inter-cultural the relationship was formed. During the interview, the researcher was informed that educational institution, working place and social event has motivated them for entering the inter-ethical relationship. Further research would explore other factors such as the social networking site and external factors influencing them to be involved in such a relationship. Through this research, we obtained a more holistic picture of the issues, which could be an important lesson for the researchers. This research process might be helpful for other researchers to build more creativity in qualitative research.

\section{Acknowledgments}

Research for this project was supported by Bangladesh Social Development Academy (BSDA). We gratefully acknowledge the study respondents who consented to voluntarily participation in the study and provided valuable information.

\section{References}

Andrzej K and. Peter A. L (2013). Intermarriage among Arabs in the United States: Patterns, Causes and Significance. IUSSP General Population Conference, Busan. 26 to 31 August 2013. 


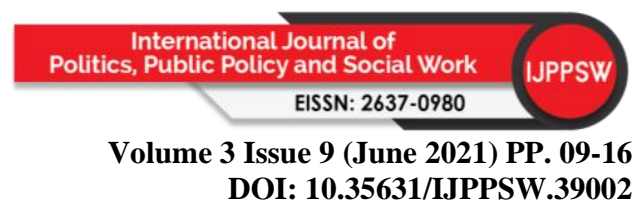

Baharuddin, R. Juhari R. and Tan J. P (2003). Perkahwinan campur di Malaysia. Serdang, Penerbit Universiti Putra Malaysia.

Becker G. S. (1973). A theory of marriage: Part I, Journal of Political Economy. 81(4), 813846.

Becker G. S (1973a). A theory of social interactions. Journal of Political Economy. 82(6), 1063-1093.

Becker G. S (1973b). A theory of marriage: Part II, Journal of Political Economy.” 82(2) 1126.

Bogdan R. and. Biklen S. K (1992). Qualitative research for education: an introduction to theory and methods". London: Allwyn and Bacon.

Brown J. A. (1987). Casework contacts with black-white couple. Social Casework. The Journal of Contemporary Social Work, 68. 24-30.

Burrell, N. A., \& Fitzpatrick, M. A. (1990). The psychological reality of marital conflict. In D. D. Cahn (Ed.), Intimates in conflict: A communication perspective (pp. 167-185). Hillsdale, NJ: Lawrence Erlbaum.

Cheryl Crippen and Leah Brew (2007). Intercultural Parenting and the Transcultural Family: A Literature Review. The Family Journal. 15:107

Chin K. K. (1994). Out-of-town brides: International marriage and wife abuse among Chinese immigrants. Journal of Comparative Family Studies, 25,53- 70

Giok H. P. and Nidzam S. (2013). Choose one! Challenges of inter-ethnic marriages in Malaysia. Asian Social Science, 9 (17), 269-277.

Hegar, R. L., and Greif, G. L 1994). Parental abduction of children from interracial and crosscultural marriages. Journal of Comparative Family Studies, 25, 135-138

Hsuan R. (2014). A narrative Inquiry into the lived experiences of Chinese-White Heterosexual couples within a Canadian context". A thesis submitted in conformity with the requirements for the degree of Doctor of Philosophy. Unpublished Thesis. Department of Applied Psychology and Human Development, Ontario Institute for Studies in Education. University of Toronto. Available at: https://tspace.library.utoronto.ca/bitstream/1807/65769/1/Wu_Rong\%20Hsuan_20140 6_PhD_thesis.pdf

Ismail R. (2003). An evaluation of marital relationship and its implications for cross cultural counselling of Kadazandusun and Sino-Kadazan couples in Sabah, Malaysia." Asia Pacific Journal of Social Work and Development, 13(1),99-116.

K Chin (1994). Out-of-town brides: International marriage and wife abuse among Chinese immigrants. Journal of Comparative Family Studies, 25 53- 70

Lassi, L. and S. Minna (2003). Intercultural Marriages and Consideration of Divorce in Finland: Do value differences matter'? Working papers, no 4.

Lee, J., \& Bean, F. D. (2004). America's changing color lines: Immigration, race/ethnicity, and multiracial identification. Annual Review of Sociology, 30, 221-243.

Luke, C., \& Carrington, V. (2000). Race matters. Journal of Intercultural Studies, 21(1), 5-20

Maxwell J. A (2006). Qualitative Research Design: An Interactive Approach". (2nd ed.). Thousand Islands, Sage.

Owen, J. D. (2002). Mixed matches: Interracial marriage in Australia. Sydney, Australia: University of New South Wales Press

Qian, Z. (1999). Who intermarries? Education, nativity, region, and interracial marriage, 1980 and 1990. Journal of Comparative Family Studies,30(4), 579-580

Quinones-Mayo Y. and Dempsey P. (2005). Finding the Bicultural Balance: Immigrant Latino Mothers raising “American” Adolescents. Child Welfare, 84(5)649-667 
Volume 3 Issue 9 (June 2021) PP. 09-16 DOI: 10.35631/IJPPSW.39002

Robert, S. and J. Wooldredge. (1989) Marriage Choices in North Carolina and Virginia. 1969 71 and 1979-81". Journal of Marriage and the Family.51: 465-481.

Shenton, A. K (200). Strategies for ensuring trustworthiness in qualitative research projects. Education for Information, 22 63-75

Stephen K. A. and Kasim H (2015). Qualitative and quantitative research paradigms in business research: a philosophical reflection. European Journal of Business and Management, 7 (3) 217-224.

Tan J. P (2012). Inter-ethnic and mono-ethnic families: Examining the association of parenting and child emotional and behavioural adjustment. Pertanika Journal of Social Science and Humanities, 20(1) 165-178.

Troy, A. B. Lewis-Smith, J. and Laurenceau J. P. (2006). Interracial and interracial romantic relationships: The search for differences in satisfaction, conflict, and attachment style". Journal of Social and Personal Relationships, 23, 65-80

Tzeng, J. M. (2000). Ethnically heterogamous marriages: The case of Asian Canadians. Journal of Comparative Family Studies, 31(3), 321-340

Xinmiao Z. (2014), Factors Contributing to Personal Commitment in Chinese Interethnic Couples. An International Journal of Personal Relationship, 8 (1), 2-50 